\title{
Incidence of childhood brain and other non-haematopoietic neoplasms near nuclear sites in Scotland, 1975-94
}

\author{
L Sharp, P A McKinney, R J Black
}

Department of Medicine and Therapeutics, University of Aberdeen, Foresterhill House Annexe, Foresterhill, Aberdeen AB25 2DZ, Scotland, UK

L Sharp

Information and Statistics Division, Scottish National Health Service, Trinity Park House, South Trinity Road,

Edinburgh EH5 3SQ, Scotland, UK

P A McKinney

R J Black

Paediatric Epidemiology Group, University of Leeds, 32 Hyde Terrace, Leeds LS2 9LN, England, UK P A McKinney

Unit of Descriptive Epidemiology, International Agency for Research on Cancer, 150 Cours Albert Thomas, 69372 Lyon Cedex 08, France R J Black

Correspondence to: Dr L Sharp, Department of Medicine and Therapeutics, University of Aberdeen, Foresterhill House Annexe, Foresterhill, Aberdeen AB25 2DZ, Scotland, UK

Accepted 30 November 1998

\begin{abstract}
Objectives-To examine the risk of cancers other than leukaemia and nonHodgkin's lymphoma in children resident in the vicinity of nuclear sites in Scotland. Methods-The study dataset comprised registrations of cancer other than leukaemia and non-Hodgkin's lymphoma diagnosed in children aged under 15 in the period 1975-94. These were validated for completeness and accuracy and analysed in two groups: (a) tumours of the central nervous system and $(b)$ other malignant tumours (excluding leukaemia and nonHodgkin's lymphoma). Around each nuclear site observed cases (O) were enumerated and expected numbers (E) calculated with adjustment for age, sex, deprivation, and an urban-rural category. Stone's maximum likelihood ratio test (MLR) was used to determine whether there was any evidence of increased risk of these neoplasms among children living within $25 \mathrm{~km}$ of one of the nuclear sites investigated. The significance level of each MLR statistic was estimated by simulation.

Results-More tumours of the central nervous system were observed than expected within $25 \mathrm{~km}$ of Dounreay $(\mathrm{O} / \mathrm{E}=1.14)$, Hunterston (1.14), and Rosyth (1.22). These results were based on 2, 26, and 136 observed cases, respectively. The unconditional MLR was significant only for Rosyth $(p=0.006)$. The conditional application of the MLR test for Rosyth was not significant $(p=0.771)$. For the group of other malignant neoplasms, the unconditional MLR test was not significant for any of the seven sites.

Conclusions-There was no evidence for generally increased risk of either tumours of the central nervous system or other malignant tumours in children living near nuclear sites. The significant excess of tumours of the central nervous system around Rosyth is likely to be due to the high incidence of these tumours in east central Scotland. Further investigations in this area are warranted.

(Occup Environ Med 1999;56:308-314)
\end{abstract}

Keywords: cancer; children; nuclear sites

In 1986, a public local inquiry was held into a proposed development of the Dounreay nuclear reprocessing plant in Caithness,
Scotland. ${ }^{1}$ This inquiry heard that there was evidence of a marked excess of leukaemia in people under 25 resident in the vicinity of the nuclear site. ${ }^{2}$ The Secretary of State for Scotland referred this finding to the Committee on Medical Aspects of Radiation in the Environment (COMARE). Because an excess of leukaemia had also been found near Sellafield, the only other reprocessing plant in the United Kingdom, ${ }^{3}$ the committee concentrated its investigations and advice on leukaemia in the Dounreay area ${ }^{4}$ : however, its original intention had been to study cancer in those living around all seven nuclear facilities in Scotland.

This study forms part of a systematic programme of investigation of the incidence of cancer in children living in the vicinity of all nuclear sites in Scotland, undertaken for COMARE. The initial stage in this programme was to conduct a validation exercise on registrations of childhood cancer, to ensure uniform levels of case ascertainment and diagnostic accuracy in areas around nuclear sites and elsewhere. This exercise was completed first of all for leukaemia and non-Hodgkin's lymphomas. In 1996, we reported the incidence of these tumours in the childhood populations living near the seven nuclear sites in Scotland, ${ }^{5}$ using statistical techniques that permit analysis of disease risk in the proximity of a point source. ${ }^{6-9}$ The validation of registrations of other forms of childhood cancer has recently been completed. This provides the opportunity to evaluate, for the first time, the risk of cancers other than leukaemia and non-Hodgkin's lymphoma in children living near nuclear sites in Scotland.

Data and methods

CHILDHOOD CANCER DATA

Registrations of childhood cancer in Scotland were validated before analysis. Details of all cancers diagnosed in children aged less than 15 years in the period 1975-90 were extracted from the Scottish National Cancer Registry. Registration before 1975 is thought to have been incomplete ${ }^{10}$ and postcodes have been recorded routinely only since 1975 . The cancer registrations were matched to the Scottish Morbidity Record for Inpatients (SMR1) and the United Kingdom National Registry of Childhood Tumours to identify missed registrations, with collaborating pathologists identifying missed cases from searches of hospital and pathology records. The full dataset was then subjected to diagnostic validation, with 


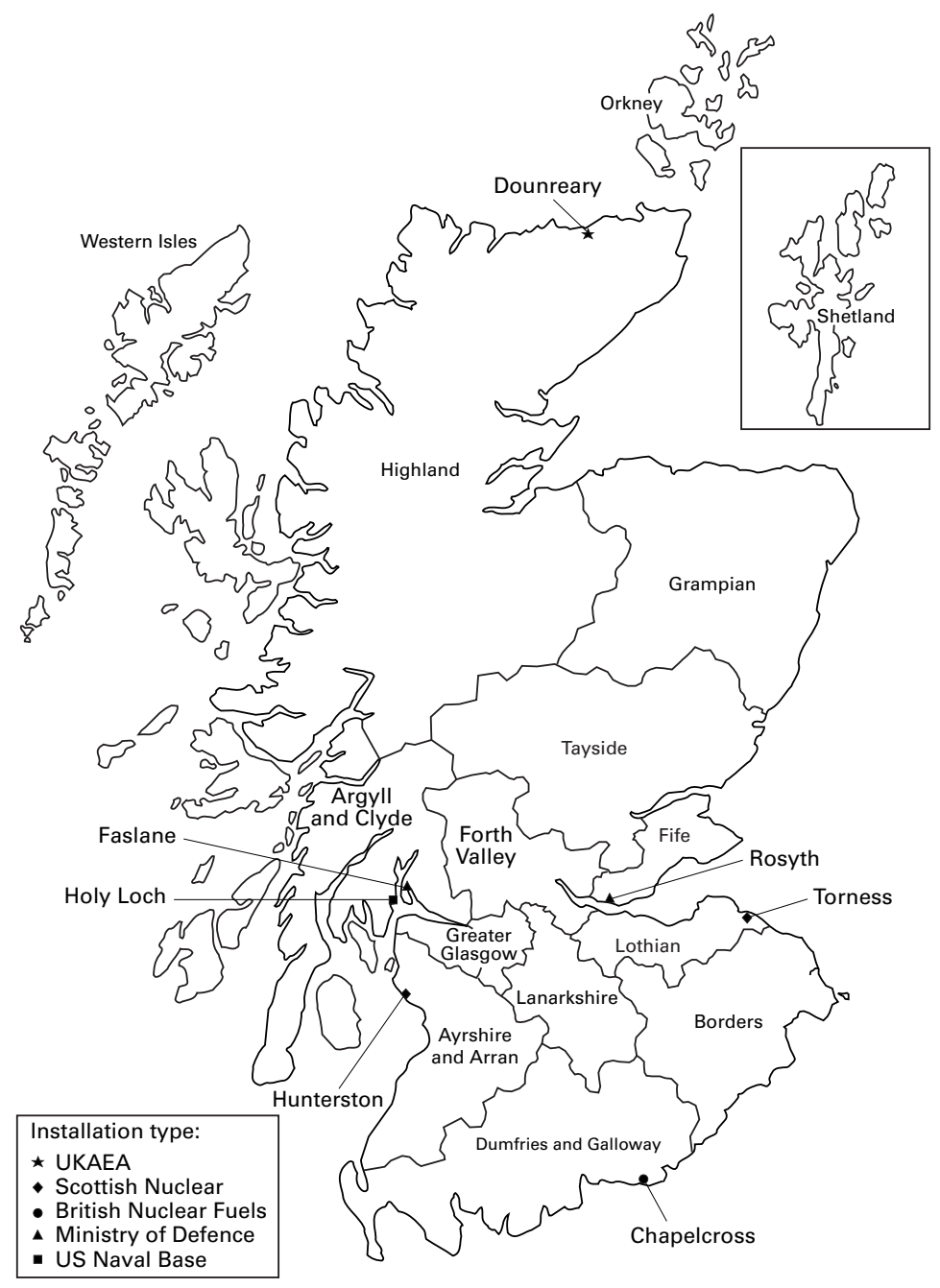

Figure 1 Locations of nuclear sites and boundaries of health board areas in Scotland.

panel review of slides where possible, and verification of case details from medical records. Childhood cancers diagnosed in the years 1991-4 were obtained from the Scottish case control study of childhood leukaemia and cancer where cases are validated routinely. ${ }^{11}$ Further details of the validation of brain and other central nervous system (CNS) tumours have been published. ${ }^{12}$

The study dataset for 1975-94 comprised 1539 cases of Hodgkin's disease and other non-lymphatic, non-haematopoietic malignancies in the age group 0-14 years. The Birch and Marsden scheme, ${ }^{13}$ based on ICD-O, ${ }^{14}$ was used to group the tumours into two categories for analysis: (a) central nervous system tumours and miscellaneous intracranial and intraspinal neoplasms and (b) other solid tumours including retinoblastoma, renal, hepatic, and bone tumours, soft tissue sarcomas, germ cell trophoblastic and other gonadal neoplasms, and carcinoma and other malignant neoplasms, and Hodgkin's disease. This separation into two groups was a compromise between the desire to investigate clinically and biologically distinct subtypes and the necessity for sufficient numbers of cases for statistical analysis. Only the tumours of the CNS comprised large enough numbers for separate consideration.

\section{NUCLEAR SITES}

The seven nuclear sites in Scotland were included-namely, the Dounreay reprocessing plant, the electricity generating stations, Chapelcross, Hunterston, and Torness, and sites where nuclear submarines have been berthed, Holy Loch, Faslane, and Rosyth (fig 1). With the exception of Torness, all of the sites started operations before the start of the study period, 1975. ${ }^{5}$ Torness became operational in 1989 and has been included in the analysis for completeness. Each nuclear site was considered separately; no pooled analyses were undertaken.

\section{CONSTRUCTION OF STUDY ZONES AND}

CALCULATION OF POPULATION ESTIMATES

Our basic geographical units of analysis were 1981 census enumeration districts (EDs). In accord with previous studies, ${ }^{5}{ }^{15}$ a study zone was constructed around each nuclear site from 1981 enumeration districts with population weighted centroids within $25 \mathrm{~km}$ of the grid reference of the site. The analyses for Faslane and Holy Loch are not independent as the sites are situated only $11 \mathrm{~km}$ apart. Chapelcross is close to the English border and the part of the $25 \mathrm{~km}$ zone which is not in Scotland was not included in the analysis; however, it was decided to retain this site in the analysis for completeness.

Age and sex specific population counts for enumeration districts were obtained from the censuses of 1971 and 1981. Population counts are available for output areas from the 1991 census. We mapped each output area to the closest 1981 ED. Because of the underenumeration in the latest census (estimated to be $-1.4 \%$ for those aged under 15$),{ }^{5}$ we adjusted the 1991 population counts such that the adjusted total population over local government districts was equal to the revised population estimates of the Registrar General for Scotland. ${ }^{16}$ Age and sex specific population estimates for each ED for the study period 1975-94 were calculated as a weighted average of the population counts for 1971 and 1981 and the adjusted counts for 1991 .

\section{CALCULATION OF EXPECTED NUMBERS}

Following the method of Carstairs and Morris ${ }^{17}$ a deprivation score was computed for each 1981 ED. From this, five deprivation categories were created each containing a quintile of the total population. A five level urban-rural residence indicator was constructed for each 1981 ED as a weighted average of the urban-rural indicators for the postcode units within the ED. Age, sex, deprivation, and urban-rural specific rates of (a) central nervous system tumours and (b) other malignant neoplasms were computed for all Scotland and applied to the EDs to obtain expected numbers of cases. 
Table 1 Cases ( $(\%))$ in study dataset by diagnostic group, 0-14 years old, 1975-94

\begin{tabular}{llll}
\hline $\begin{array}{l}\text { Birch and } \\
\text { Marsden code }\end{array}$ & Diagnostic group & Cases (n) & $\%$ \\
\hline 2.1 & Hodgkin's disease & 111 & 7.2 \\
3 & Central nervous system and miscellaneous intracranial & 601 & 39.1 \\
& and intraspinal neoplasms & 179 & 11.6 \\
4 & Sympathetic nervous system tumours & 86 & 5.6 \\
5 & Retinoblastoma & 133 & 8.6 \\
6 & Renal tumours & 19 & 1.2 \\
7 & Hepatic tumours & 115 & 7.5 \\
8 & Malignant bone tumours & 144 & 9.4 \\
9 & Soft tissue sarcomas & 72 & 4.7 \\
10 & Germ cell, trophoblastic, and other gonadal tumours \\
11 & Carcinoma and other malignant epithelial neoplasms & 74 & 4.8 \\
12 & Other and unspecified malignant neoplasms & 5 & 0.3 \\
Total & & 1539 & 100 \\
\hline
\end{tabular}

Table 2 Number of enumeration districts in study zone * and population under 15 years of age averaged over 1975-94, by nuclear site

\begin{tabular}{lcl}
\hline Nuclear site & $\begin{array}{l}\text { Enumeration } \\
\text { districts }(n)\end{array}$ & $\begin{array}{l}\text { Average population } \\
\text { aged }<15\end{array}$ \\
\hline $\begin{array}{l}\text { Reprocessing plant: } \\
\quad \text { Dounreay }\end{array}$ & 54 & 3190 \\
$\begin{array}{l}\text { Electricity generating plants: } \\
\quad \text { Chapelcross }\end{array}$ & 187 & 10579 \\
$\quad$ Hunterston & 659 & 41734 \\
$\quad \begin{array}{l}\text { Torness } \\
\text { Submarine bases: }\end{array}$ & 155 & 7758 \\
$\quad$ Faslane & 648 & 41586 \\
$\quad$ Holy Loch & 719 & 43759 \\
$\quad$ Rosyth & 3064 & 183185 \\
\hline
\end{tabular}

$\star<25 \mathrm{~km}$ radius from site.

STATISTICAL TESTS

Several statistical tests for the analysis of disease incidence in the vicinity of a point source of possible environmental risk have been developed. ${ }^{6-9} 1518$ Previous evaluation indicates that, for analyses based on Scottish EDs which include point sources in both densely and sparsely populated areas, the most powerful test is Stone's maximum likelihood ratio (MLR) test. ${ }^{5}$ This test may be applied in the unconditional or conditional form. The unconditional MLR test is sensitive both to the spatial pattern of the observed cases relative to the point source and the overall ratio of the observed to expected cases in the study area. The conditional form of the test is designed to detect patterns of decreasing risk relative to a point source, given the overall incidence in the study area, which may be higher or lower than expected.

The unconditional MLR test was used to determine whether there was evidence of increased risk of (a) tumours of the CNS or $(b)$ other malignant neoplasms (other than leukae- mia and non-Hodgkin's lymphoma) in relation to proximity to each nuclear site. In each analysis, the one tailed significance level of the observed MLR for each nuclear site was determined from 1000 simulations of cases sampled from the Poisson distribution. In analyses where the result of the unconditional MLR test was significant (at the 5\% level) the conditional form of the MLR was also applied with the significance level determined from 1000 simulations of cases sampled from the multinomial distribution.

For descriptive purposes observed to expected ratios were calculated with exact $95 \%$ confidence intervals (95\% CIs) based on the Poisson distribution. ${ }^{19}$ To aid interpretation for particular sites, cumulative observed to expected ratios of cases with distance, and the distribution of the childhood population across the study zone were plotted.

\section{Results}

Table 1 shows the numbers and percentages of the 1539 cases included in the study dataset classified by diagnostic group. The numbers of 1981 EDs in the study zones around each nuclear site are presented in table 2 together with the average childhood population resident in each area during 1975-94. The population densities around the sites vary greatly with a 57-fold difference in the population in the least (Dounreay, population 3190) compared to the most populous (Rosyth, population 183 185) zones.

\section{CENTRAL NERVOUS SYSTEM TUMOURS}

Table 3 shows the observed $(\mathrm{O})$ and expected (E) numbers of cases of tumours of the CNS, the $\mathrm{O} / \mathrm{E}$ ratios with $95 \% \mathrm{CIs}$, and levels of significance of the unconditional MLR test for the seven nuclear sites.

In the zone within $25 \mathrm{~km}$ of Dounreay, two cases were observed compared with 1.76 expected. More cases were observed than expected in the zones around Hunterston (1.14) and Rosyth (1.22). The unconditional MLR test statistic was significant only for the zone around Rosyth $(\mathrm{p}=0.006)$. The conditional MLR test was applied to the data around Rosyth; this was not significant $(p=0.771)$, indicating that there was no trend of decreasing risk with distance from the site. Around the remaining four sites fewer cases were observed than expected.

Table 3 Observed $(O)$ and expected $(E) *$ numbers of cases in study zone, observed to expected ratios $(O / E)(95 \%$ CI), and p values of the unconditional MLR test + , by nuclear site, 0-14 years old, 1975-94: central nervous system tumours $\neq$, and other malignant neoplasmsS

\begin{tabular}{|c|c|c|c|c|c|c|c|c|c|c|}
\hline \multirow[b]{2}{*}{ Nuclear site } & \multicolumn{5}{|c|}{ Central nervous system tumours } & \multicolumn{5}{|c|}{ Other malignant neoplasms } \\
\hline & $O$ & $E$ & $O / E$ & $95 \% C I$ & $\begin{array}{l}\text { MLR } \\
\text { p Value }\end{array}$ & $O$ & $E$ & $O / E$ & $95 \% C I$ & $\begin{array}{l}\text { MLR } \\
p \text { Value }\end{array}$ \\
\hline Dounreay & 2 & 1.76 & 1.14 & 0.13 to 4.10 & 0.746 & 1 & 2.53 & 0.40 & 0.01 to 2.20 & 0.987 \\
\hline Chapelcross & 3 & 6.36 & 0.47 & 0.09 to 1.38 & 0.959 & 14 & 9.25 & 1.51 & 0.83 to 2.54 & 0.073 \\
\hline Hunterston & 26 & 22.88 & 1.14 & 0.74 to 1.67 & 0.353 & 36 & 35.55 & 1.01 & 0.71 to 1.40 & 0.523 \\
\hline Torness & 2 & 4.45 & 0.45 & 0.05 to 1.62 & 0.944 & 2 & 6.16 & 0.32 & 0.04 to 1.17 & 0.751 \\
\hline Faslane & 15 & 21.52 & 0.70 & 0.39 to 1.15 & 0.959 & 34 & 37.79 & 0.90 & 0.62 to 1.26 & 0.831 \\
\hline Holy Loch & 18 & 22.74 & 0.79 & 0.47 to 1.25 & 0.835 & 34 & 39.12 & 0.87 & 0.60 to 1.21 & 0.883 \\
\hline Rosyth & 136 & 111.55 & 1.22 & 1.02 to 1.44 & 0.006 & 182 & 175.59 & 1.04 & 0.89 to 1.20 & 0.296 \\
\hline
\end{tabular}

*Adjusted for age group, sex, deprivation, and urban-rural category.

†From 1000 simulations, with cases sampled from Poisson distribution, for each nuclear site.

$\ddagger$ Birch and Marsden diagnostic group 3 .

$§$ Birch and Marsden diagnostic groups 2.1 and $4-12$. 

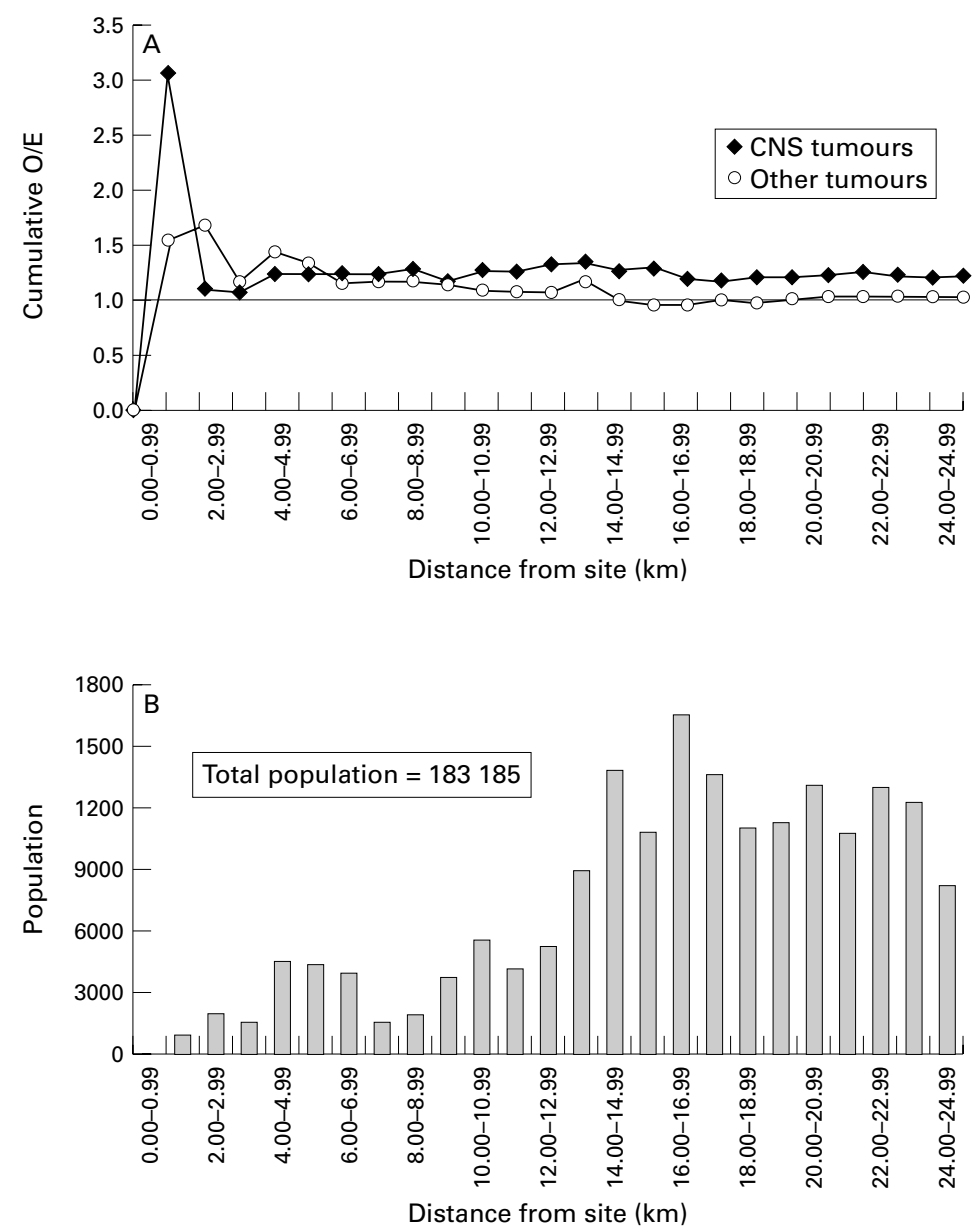

Figure 2 (A) Ratio of cumulative $O / E$ cases by distance from the site and tumour group, 0-14 years, 1975-94, Rosyth. (B) Average population of enumeration districts within 25 $\mathrm{km}$ study zone, by distance from site, 0-14 years, 1975-94, Rosyth.

Of the 136 tumours in the childhood population around Rosyth, $14(10.3 \%)$ were ependymomas, $65(47.8 \%)$ astrocytomas, 30 $(22.1 \%)$ medulloblastomas, $17(12.5 \%)$ other gliomas, and $10(7.4 \%)$ other types. The relative frequencies of these subtypes in this area did not differ from the rest of Scotland $\left(\chi^{2}=2.22(4 \mathrm{df}) ; \mathrm{p}=0.694\right)$. Of the cases, $26 \%$ were diagnosed in $1975-9,28 \%$ in $1980-84$, $26 \%$ in $1985-89$, and $20 \%$ in $1990-94$. As in the rest of Scotland, there was a male excess of cases ( 76 boys compared with 60 girls). The age distribution of the 136 cases did not differ from that in the rest of Scotland $\left(\chi^{2}=0.807\right.$ ( 2 $\mathrm{df}) ; \mathrm{p}=0.670) ; 41(30 \%)$ were diagnosed in those under 5 years of age, $53(39 \%)$ in those 5-9 years, and $42(31 \%)$ in the 10-14 age group.

Figure $2 \mathrm{~A}$ and $\mathrm{B}$ shows the cumulative $\mathrm{O} / \mathrm{E}$ ratio of tumours of the CNS and the distribution of the childhood population with distance from the Rosyth dockyard, respectively. An excess of cases is apparent across the entire populated area of the study zone. There is a localised peak comprising two cases observed compared with 0.65 expected $(\mathrm{O} / \mathrm{E}=3.06)$ in the small population resident between $1-2 \mathrm{~km}$ from the site (population=1009), and a small excess of observed compared with expected incidence throughout the remainder of the 25 $\mathrm{km}$ zone.

OTHER MALIGNANT NEOPLASMS

In the study zones around Dounreay, Torness, Faslane, and Holy Loch fewer cases of other malignant neoplasms were observed than expected (table 3). For Hunterston and Rosyth the observed numbers of cases were consistent with expectation $(\mathrm{O} / \mathrm{E}=1.01$ and 1.04 respectively) and the MLR was not significant for either site. Fourteen cases were observed around Chapelcross compared with 9.25 expected $(\mathrm{O} / \mathrm{E}=1.51)$. These 14 cases were not of unusual types comprising one case of Hodgkin's disease, one neuroblastoma, one renal, and one germ cell tumour, three bone cancers, four soft tissue sarcomas, and three other epithelial neoplasms. The MLR test for Chapelcross was not significant $(\mathrm{p}=0.073)$.

\section{Discussion}

Studies of cancer rates around nuclear installations have been subject to the criticism that the choice of fixed spatial or temporal boundaries can obscure or enhance locally high risk..$^{21} \mathrm{We}$ embarked on this analysis with a clear initial null hypothesis that the risk of cancers other than leukaemia and non-Hodgkin's lymphoma was not increased in children living in the vicinity of nuclear sites. The study zones were defined as in earlier analyses. ${ }^{5}$ The categorisation of the data was conservative and determined before the analysis. With no hypotheses regarding specific periods or age groups, we considered the full period for which high quality childhood cancer data are available, 197594 , and the entire childhood age range, 0-14 years.

To consider the possibility of different levels of case ascertainment in areas around nuclear sites and elsewhere, ${ }^{22}$ we preceded our analysis with validation of all childhood cancers in Scotland. Identical validation procedures were used irrespective of where the cases were resident. A high degree of completeness was ensured by cross checking cancer registrations against independent data sources with national coverage. Moreover, as results of small area studies may be influenced by relatively minor data misclassifications, we also attempted to verify the diagnostic, demographic, and residential details of all cases. Postcodes of residence found to be incorrectly recorded $(8 \%$ of the tumours of the CNS) $)^{12}$ were revised. Hence we are confident that there are no systematic geographical variations in case ascertainment in the dataset and that the cases have been allocated accurately to enumeration districts and study zones in the analysis.

The excess of leukaemia and non-Hodgkin's lymphoma in children and young people resident close to the Dounreay nuclear installation has been well described, has persisted into this decade, and does not seem to be accounted for by the rural nature and relatively high socioeconomic status of the population of the area (at least to the extent that these phenomena can be measured). ${ }^{5}$ In this study we noted a deficit of other forms of cancer in the 
childhood population living near the site, with a total of three cases observed (two tumours of the CNS and one other neoplasm) compared with 4.29 expected. The overall deficit of cancers other than leukaemia and non-Hodgkin's lymphoma is consistent with previous investigations in the Dounreay area. ${ }^{23}$

Fourteen cases of cancers other than tumours of the CNS were found in children resident near to Chapelcross compared with 9.25 expected. The MLR test did not reach significance $(p=0.073)$. Our analysis only considered that part of the $25 \mathrm{~km}$ zone around Chapelcross that lies within Scotland. The English part of the zone was excluded because, firstly, the numerator data were incompatible due to the specific validation of the Scottish cases and the periods for which data were available, and secondly, the practical difficulties in combining ward level population data from the censuses of England and Wales with the ED level population data from the censuses of Scotland. In a parallel analysis based on wards, 48 cases of childhood cancers other than leukaemia and non-Hodgkin's lymphoma were observed in the period 1966-87 compared with 42.9 expected in the entire $25 \mathrm{~km}$ zone around Chapelcross $(\mathrm{O} / \mathrm{E}=1.12)$ (J Bithell, GJ Draper, personal communication). This is consistent with our finding for cancers other than leukaemia and non-Hodgkin's lymphoma combined (three tumours of the CNS plus 14 other neoplasms, 15.61 expected, O/E-1.09, 95\% CI $0.63-1.74)$. In the ward based analysis, as in our analyses, the test for an association between risk and proximity to the site was not significant.

An excess of tumours of the CNS was found in the study zone around Rosyth nuclear dockyard $(\mathrm{O}=136, \mathrm{E}=111.55)$ and the unconditional MLR test was significant $(\mathrm{p}=0.006)$. There were no differences between the distributions of the subtypes age or sex of the cases in the study zone around Rosyth and in the rest of Scotland. The distribution of the cases across the Rosyth study zone shows a highly localised excess at $<2 \mathrm{~km}$ from the site (fig $2 \mathrm{~A}$ ) accounted for by two cases compared with 0.65 expected $(\mathrm{O} / \mathrm{E}=3.06)$. It is likely that the significant MLR result is heavily dependent on these two cases. The histology of both cases has been reviewed and verified; one was a glioma diagnosed in 1975 in a child aged 6, the other a pilocytic astrocytoma in a child of 2 years in 1987.

Relatively little is known about the aetiology of cancer of the brain and CNS in children. Several dominantly inherited syndromes confer increased risk, and familial aggregations of cases have been found, ${ }^{24}$ but the proportion of cases likely to be attributable to genetic factors is unknown. The most consistently reported environmental risk factor is exposure to radiation, either before birth through maternal $x$ ray films during pregnancy, ${ }^{25}$ or through diagnostic $^{26}$ or therapeutic ${ }^{27} x$ ray films in childhood. However, the low dose and short exposure time of modern $x$ ray films are thought to confer a minimal risk. ${ }^{24}$ It has been postulated that prenatal and early childhood exposure to $\mathrm{N}$-nitroso compounds may increase risk. Preston-Martin et $a l^{26}$ showed a dose-response with maternal consumption of cured meat during pregnancy, a finding replicated elsewhere. ${ }^{27} 28$ There are several sources of $\mathrm{N}$-nitroso compounds in the environment and it is difficult to imagine why the Rosyth area should be different from comparison with other parts of Scotland. Some parental occupations and occupational exposures have been reported to be associated with brain tumours in offspring including employment in agriculture. ${ }^{24}$ However, Rosyth is in the highly urbanised central belt of Scotland and a relatively small proportion of the population in the area is employed in agriculture. A metaanalysis, in 1994, of seven studies estimated a relative risk for brain cancer in children associated with residential proximity to electricity transmission and distribution equipment of 1.89 (95\% CI 1.34 to 2.67$){ }^{29}$ but more recent studies of childhood brain tumours relative to residential magnetic fields have found little evidence of an association. ${ }^{30}{ }^{31}$ Other potential risk factors for childhood brain and CNS tumours have been explored but there have been few consistent findings.

Rosyth dockyard is in Fife Health Board area and situated on the north of the Firth of Forth (fig 1). The $25 \mathrm{~km}$ study zone around the site extends into the city of Edinburgh. It is likely that most of the neoplasms of the CNS were diagnosed and treated in the Royal Hospital for Sick Children in Edinburgh. It is possible that the observed excess could be an artefact of better ascertainment in the area close to this specialist centre. However, examination of the cumulative $\mathrm{O} / \mathrm{E}$ ratio with distance from the site shows a deficit of cases in the immediate vicinity, followed by a peak in incidence at 1-1.99 km, then by a more modest excess throughout the remainder of the study area (fig 2 A). This would suggest that differential ascertainment does not account for the increased risk around Rosyth. Evidence from epidemiological studies of the relation between measures of socioeconomic status and risk of childhood brain tumours is limited and inconsistent. ${ }^{124}{ }^{24}{ }^{33} \mathrm{McKinney}$ et al ${ }^{12}$ showed a substantially higher incidence of these tumours in children resident in the most affluent areas of Scotland than in the most deprived. However, our analysis included adjustments for deprivation and urban-rural residence. Therefore it seems unlikely that the sociodemographic characteristics of the study area account for the observed excess.

The study zone around Rosyth extends into three health boards, and of the population under $1560 \%$ are resident in Lothian, 24\% in Fife, and $16 \%$ in Forth Valley. Analysis of the validated set of tumours of the CNS for the period 1975-90 showed that incidence was higher than the Scottish average in all three health boards; the standardised registration ratios were 138 (95\% CI 110 to 171$), 156$ (114 to 207), and 133 (91 to 188) for Lothian, Fife, and Forth Valley, respectively. ${ }^{12}$ It is possible, therefore, that part of the overall excess in the study zone around Rosyth could be accounted 
for by the higher incidence in these areas of east central Scotland than the country as a whole. This interpretation is supported by the negative result of the conditional MLR test, which would be sensitive specifically to patterns of decreasing risk with distance of residence from Rosyth. There was no evidence of an increased risk of neoplasms of the CNS around the other Scottish sites at which nuclear submarines have been overhauled (Faslane $\mathrm{O} / \mathrm{E}=0.70$; Holy Loch $\mathrm{O} / \mathrm{E}=0.79$ ). Therefore, it seems most likely that the excess around Rosyth is due, not to factors specifically associated with the site itself, but rather is a result of the unexplained high incidence of tumours of the CNS in that area of Scotland. Having said this, the high risk in east central Scotland warrants further investigation.

Few investigations of nuclear sites in the United Kingdom and internationally have reported results for cancers other than leukaemia in children. In the cohort of children born in Seascale, close to Sellafield, an excess of mortality from cancers other than leukaemia and non-Hodgkin's lymphoma up to 1984 was found $(\mathrm{O} / \mathrm{E}=3.15),{ }^{34}$ but, in the years since 1984, there has been no evidence of increased incidence of these tumours in children in the area. ${ }^{35}$ In the $0-4$ age group resident within 10 $\mathrm{km}$ of Aldermaston and Burghfield there was evidence of a small but significantly raised registration rate for other forms of childhood cancer during $1971-82 .{ }^{36}$ Results of an analysis of mortality from brain cancer in people under 25 in areas near 22 nuclear sites in England and Wales were inconsistent. ${ }^{22} \mathrm{~A}$ significantly reduced standardised mortality ratio (SMR) for malignant brain cancers and an increased SMR for Hodgkin's disease in areas around six French nuclear sites did not persist after correction for multiple tests. ${ }^{37}$ The risk of all malignancies other than acute leukaemia and non-Hodgkin's lymphoma in areas near 20 nuclear plants in the former West Germany was not higher than in control areas. ${ }^{38}$ However, in the area within $25 \mathrm{~km}$ of the Würgassen power plant in West Germany the incidence of tumours of the CNS was found to be higher than the national rate, particularly so within 5 $\mathrm{km}$ of the site. $^{39}$ Zaridze et al reported an increasing trend, of borderline significance, of brain tumours in children in association with increasing proximity to former nuclear test sites above ground in Kazakhstan, but the results were not adjusted for rural residence. ${ }^{40}$ None of these analyses used modern statistical techniques designed to investigate risk of disease associated with proximity to a point source and some considered mortality data which are likely to be less accurate diagnostically than incidence data. Despite this, it would seem reasonable to conclude that there is no strong evidence for a generally increased risk of cancers of the CNS or other cancers (other than leukaemia and non-Hodgkin's lymphoma) in children living near nuclear installations. The results of our study reinforce this conclusion.

\section{Conclusion}

We found no evidence for generally increased risks of either neoplasms of the CNS or other solid tumours and Hodgkin's disease in children living near nuclear sites in Scotland during 1975-94. A significant excess risk of tumours of the CNS was found in the study zone around Rosyth dockyard. This finding is likely to be due to a unexplained high incidence of tumours of the CNS in that part of the country. Further investigation of tumours of the CNS in east central Scotland is warranted.

We are grateful to all the clinicians, haematologists, and pathologists involved in the validation of the childhood cancer cases, particularly Drs J Ironside, J Keeling, R Reid, N Smith, and A Howatson. Elaine Harkness provided invaluable administrative and statistical assistance. We thank Dr John Clarke for providing hospital discharge data and the National Registry of Childhood Tumours in Oxford for providing details of cases from Scotland. Thanks are also due to the directors and staff of the regional and national cancer registries in Scotland and the staff of the Scottish Case Control Study of Childhood Leukaemia and Cancer for assisting with the validation study and for providing data for analysis. Veronica Harris compiled the dataset for analysis. Dr John Bithell kindly provided computer programs to calculate the MLR test statistic. We thank Dr their comments on an earlier draft of the paper.

1 Bell AG. Report of the Dounreay EDRP public local inquiry relating to the planning application for the siting of the European demonstration plant (EDRP) for fast reactor fuel. Caithness, 7 April to 25 November 1986. Edinburgh: Scottish Office, April 1989.

2 Heasman MA, Urquhart JD, Kemp IW, et al. Childhood leukaemia in northern Scotland. Lancet 1986;i:266, 355.

3 Black D. Investigation of the possible increased incidence of cancer in West Cumbria. London: The Stationery Office, 1984. 4 Committee on Medical Aspects of Radiation in the Environment (COMARE) Second Report. Investigation of the possible increased incidence of leukaemia in young people near the Dounreay Nuclear Establishment, Caithness, Scotland. London: HMSO, 1988.

5 Sharp L, Black RJ, Harkness EF, et al. Incidence of childhood leukaemia and non-Hodgkin's lymphoma in the vicinity of nuclear sites in Scotland, 1968-93. Occup Environ Med 1996;53:823-31.

6 Stone RA. Investigation of excess environmental risks around a putative source: statistical problems and a proposed test. Stats Med 1988;7:649-60.

7 Bithell JF, Stone RA. On statistical methods for analysing the geographical distribution of cancer cases near nuclear
installations. F Epidemiol Community Health 1989;43:79-85.

8 Bithell JF. Statistical methods for analysing point-source exposures. In: Elliott P, Cuzick J, English D, et al, eds. Geographical and environmental epidemiology: methods for small graphical and environmental epidemiology: methods for

9 Bithell J. The choice of test for detecting raised disease risk Bithell J. The choice of test for detecting raised dised
near a point source. Stat Med 1995;14:2309-22.

10 Black RJ, Macfarlane GJ, Maisonneuve P, et al. Cancer incidence and mortality in Scotland 1960-89. Edinburgh: Information and Statistics Division, 1995.

11 McKinney PA, Smith K, Findlay E. The Scottish case control study of childhood leukaemia and cancer: methodology and environmental measures of exposure. Health Bull (Edinb) 1995;53:222-9.

12 McKinney PA, Ironside JW, Harkness EF, et al. Registration quality and descriptive epidemiology of childhood brain
tumours in Scotland, 1975-90. Brf Cancer 1994;70:973-9.

13 Birch JM, Marsden HB. A classification scheme for childhood cancer. Int 7 Cancer 1987;40:620-4.

14 World Health Organisation. International classification of diseases for oncology. Geneva: WHO, 1976.

15 Bithell JF, Dutton SJ, Draper GJ, et al. Distribution of childhood leukaemias and non-Hodgkin's lymphomas near nuclear installations in England and Wales. BMF 1994;309: nuclear

16 Registrar General, Scotland. Annual report. Edinburgh: The Stationery Office, 1992.

17 Carstairs V, Morris R. Deprivation and health in Scotland. Aberdeen: Aberdeen University Press, 1991.

18 Urquhart J. The investigation of leukaemia incidence around sites of special interest. Nuclear Energy 1991;30:216.

19 Breslow NE, Day NE. Statistical methods in cancer research. Vol II. The design and analysis of cohort studies. Lyon: International Agency for Research on Cancer, 1987.

20 Hills M, Alexander FE. Statistical methods used in assessing the risk of disease near a source of possible environmental pollution: a review. Fournal of the Royal Statistical Society pollution: a review. fournal

21 Wakeford R, Binks K, Wilkie D. Childhood leukaemia and nuclear installations. Fournal of the Royal Statistical Society Series A 1989;152:1-26. 
22 Foreman D, Cook-Mozaffari, Darby S, et al. Cancer near nuclear installations. Nature 1987;329:499-505.

23 Black RI, Urquhart JD, Kendrick SW, et al. Incidence of leukaemia and other cancers in birth and school cohorts in the Dounreay area. BMF 1992;304:1401-5.

24 Kuijten RR, Bunin GR. Risk factors for childhood brain tumors. Cancer Epidemiol Biomarkers Prev 1993;2:277-88.

25 Stewart A, Webb J, Giles D, et al. Malignant disease in childhood and diagnostic irradiation in utero. Lancet 1956; ii: $447-8$.

26 Preston-Martin S, Yu MC, Benton B, et al. N-nitroso compounds and childhood brain tumours: a case-control study. Cancer Res 1982;42:5240-5.

27 Kuijten RR, Bunin GR, Nass CC, et al. Gestational and familial risk factors for childhood astrocytoma: results of a case-control study. Cancer Res 1990;50:2608-12.

28 McCredie M, Maisonneuve P, Boyle P. Antenatal risk factors for malignant brain tumours in New South Wales children. Int 7 Cancer 1994;56:6-10.

29 Washburn EP, Orza MJ, Berlin JA, et al. Residential proximity to electricity transmission and distribution equipment and risk of childhood leukaemia, childhood lymphoma and childhood nervous system tumours: systematic review, evaluation, and meta-analysis. Cancer Causes Control 1994 5:299-309.

30 Preston-Martin S, Navidi W, Thomas D, et al. Los Angeles study of residential magnetic fields and childhood brain tumours. Am f Epidemiol 1996;143:105-19.

31 Gurney JG, Meuller BA, Davis S, et al. Childhood brain tumour occurrence in relation to residential power line configurations, electric heating sources, and electric appliance use. Am F Epidemiol 1996;143:120-8.
32 Bunin GR, Buckley JD, Boesel CP, et al. Risk factors for the brain in young children: a report from the Children's Cancer Group. Cancer Epidemiol Biomarkers Prev 1994;3: Cancer G

33 McCredie M, Maisonneuve P, Boyle P. Perinatal risk factors for malignant brain tumours in New South Wales children. Int $\mathcal{F}$ Cancer 1994;56:11-15.

34 Gardner MJ, Hall AJ, Downes S, Terrell JD. Follow up study of children born to mothers resident in Seascale, West Cumbria (birth cohort). BMF 1987;295:822-7.

35 Draper GJ, Stiller CA, Cartwright RA, et al. Cancer in Cumbria and in the vicinity of the Sellafield nuclear installation. BMF 1993;306:89-94.

36 Committee on Medical Aspects of Radiation in the Environment (COMARE) Third Report. Chairman Professor M Bobrow Report on the incidence of childhood cancer in the West Berkshire and North Hampshire area, in which are ituated the Atomic Weapons Research Establish intch are maston and the Royal Ordnance Factory, Burghfield.London: maston and the Royal Ordnan

37 Hill C, Laplanche A. Overall mortality and cancer mortality around French nuclear sites. Nature 1990;347:755-7.

38 Michaelis J, Keller B, Haaf G, et al. Incidence of childhood malignancies in the vicinity of West German nuclear powe plants. Cancer Causes Control 1992;3:255-63.

39 Prindull G, Demuth M, Wehinger H. Cancer morbidity rates of children from the vicinity of the nuclear powe plant of Wurgassen (FRG). Acta Haematol 1993;90:90-3.

40 Zaridze D, Li N, Men T, et al. Childhood cancer incidence in relation to distance from the former nuclear testing site in Semipalatinsk, Kazakhstan. Int f Cancer 1994;59:471-5.

\section{Rejected manuscripts}

From February 1994, authors whose submitted articles are rejected will be advised of the decision and one copy of the article, together with any reviewer's comments, will be returned to them. The fournal will destroy remaining copies of the article but correspondence and reviewers' comments will be kept. 